Check for updates

Cite this: J. Mater. Chem. A, 2020, 8 , 3632

Received 12th December 2019

Accepted 7th January 2020

DOI: 10.1039/c9ta13611h

rsc.li/materials-a

\section{Mixed-dimensional $\mathrm{PdSe}_{2} / \mathrm{SiNWA}$ heterostructure based photovoltaic detectors for self-driven, broadband photodetection, infrared imaging and humidity sensing $\dagger$}

\author{
Di Wu, (D) a Cheng Jia, ${ }^{a}$ Fenghua Shi, ${ }^{\mathrm{b}}$ Longhui Zeng, ${ }^{\text {*c }}$ Pei Lin, ${ }^{\mathrm{a}}$ Lin Dong, ${ }^{\mathrm{a}}$ \\ Zhifeng Shi, iD a Yongtao Tian, ${ }^{a}$ Xinjian $\mathrm{Li}^{\mathrm{a}}$ and Jiansheng Jie (iD *d
}

\begin{abstract}
The new discovery of two-dimensional (2D) palladium diselenide $\left(\mathrm{PdSe}_{2}\right)$ films has attracted intensive research interest due to their unique asymmetric crystal structure and extraordinary optoelectronic properties, showing great potential for broadband and polarization photodetection. Herein, we have developed for the first time a self-driven, highly polarization-sensitive, broadband photovoltaic detector based on a $\mathrm{PdSe}_{2} / \mathrm{Si}$ nanowire array (SiNWA) heterostructure. Owing to the strong light confinement effect of the SiNWA and broadband light absorption of $\mathrm{PdSe}_{2}$, the present device exhibits pronounced photovoltaic behavior and excellent performance in terms of a high responsivity of $726 \mathrm{~mA} \mathrm{~W}^{-1}$, a large specific detectivity of $3.19 \times 10^{14}$ Jones, an ultrabroad spectrum response range of $0.2-4.6 \mu \mathrm{m}$, and a fast response speed to monitor nanosecond pulsed light signals. Significantly, an impressive polarization sensitivity of 75 is achieved for the heterostructure device, which is among the highest for 2D material-based photodetectors. Thanks to the outstanding imaging capability, the detector can record images in both near infrared (NIR) and mid-infrared (MIR) ranges with a decent resolution. Moreover, the device exhibits light-enhanced humidity sensing behavior with a high sensitivity and a fast response/recovery time. Given these remarkable device features, the $\mathrm{PdSe}_{2} / \mathrm{SiNWA}_{\mathrm{N}}$ heterostructure will hold great promise for high-performance, polarization-sensitive broadband photodetection, infrared imaging and humidity sensing applications.
\end{abstract}

\section{Introduction}

As the first discovered two-dimensional (2D) layered material, graphene has attracted tremendous interest due to its outstanding electrical, optical, and mechanical properties. ${ }^{1}$ Graphene has found exciting applications in a variety of fields, such as electronics, biosensors, solar cells, and photocatalysts. ${ }^{2-6}$ Despite the enormous progress, the wide application of graphene in optoelectronic devices is still impeded by disadvantages such as its gapless nature, weak light absorption, and short photocarrier lifetime. ${ }^{7,8}$ Such predicaments are a key

\footnotetext{
${ }^{a}$ School of Physics and Microelectronics, Key Laboratory of Material Physics, Ministry of Education, Zhengzhou University, Zhengzhou, Henan 450052, China

${ }^{b}$ College of Physics and Electronic Information, Anhui Normal University, Wuhu, Anhui 241000, China

${ }^{c}$ Department of Applied Physics and Materials Research Center, The Hong Kong Polytechnic University, Hung Hom, Kowloon, Hong Kong, China. E-mail: lhzeng. hfut@gmail.com

${ }^{d}$ Institute of Functional Nano \& Soft Materials (FUNSOM), Soochow University, Suzhou, Jiangsu 215123, China. E-mail: jsjie@suda.edu.cn

$\dagger$ Electronic supplementary information (ESI) available: Fig. S1-S8. See DOI: $10.1039 / \mathrm{c} 9 \operatorname{ta} 13611 \mathrm{~h}$
}

driving force for the research community towards the exploration of other promising and alternative 2D layered materials to overcome the above shortcomings of graphene. Recently, graphene-analogous 2D materials such as arsenene, ${ }^{9}$ black phosphorus, ${ }^{10}$ antimonene, ${ }^{11}$ silicone, ${ }^{12}$ and layered transition metal dichalcogenides (TMDs, $\mathrm{MoS}_{2}, \mathrm{WS}_{2}, \mathrm{WSe}_{2}$, and $\mathrm{MoSe}_{2}$ ) with exotic properties have come under the spotlight. ${ }^{13-19}$ Also, various synthetic methods such as mechanically assisted exfoliation, ${ }^{20}$ liquid phase exfoliation, ${ }^{21,22}$ molecular beam epitaxy, ${ }^{23}$ chemical vapor deposition (CVD), ${ }^{24}$ and vapor phase deposition have been employed to produce $2 \mathrm{D}$ layered materials. These $2 \mathrm{D}$ layered materials display high carrier mobility, strong lightmatter interaction, and excellent mechanical flexibility. ${ }^{25}$ Such distinctive materials properties, along with the layer-dependent bandgap, make them attractive and promising candidates for high-performance optoelectronic devices. ${ }^{26,27}$

Besides the above introduced 2D layered materials, palladium diselenide $\left(\mathrm{PdSe}_{2}\right)$, the newly studied group-10 noble metal dichalcogenide with a unique anisotropic structure, has demonstrated excellent optical and electrical properties such as good air stability, a high carrier mobility, and a wide tunable bandgap from $0 \mathrm{eV}$ (bulk) to $1.3 \mathrm{eV}$ (monolayer). These 
characteristics endow $\mathrm{PdSe}_{2}$ with the capability to construct highly polarization-sensitive, air-stable and broadband photodetectors. ${ }^{28-31}$ However, only a few studies regarding related properties of $\mathrm{PdSe}_{2}$ and $\mathrm{PdSe}_{2}$-based devices have been reported thus far. For instance, Li et al. achieved the deposition of bilayer $\mathrm{PdSe}_{2}$ islands on graphene using molecular beam epitaxy (MBE) and systemically studied their optoelectronic properties. ${ }^{32}$ Besides, Liu et al. fabricated a phototransistor based on fewlayer $\mathrm{PdSe}_{2}$ films that were mechanically exfoliated from the bulk form, showing a high mobility of $216 \mathrm{~cm}^{2} \mathrm{~V}^{-1} \mathrm{~s}^{-1}$ dominated by electron transport behavior. ${ }^{33}$ Recently, Zhang et al. developed high-performance photoconductors based on 2D $\mathrm{PdSe}_{2}$ flakes, revealing an impressive responsivity of $708 \mathrm{~A} \mathrm{~W}^{-1}$ and an EQE of $82700 \%$ under 1064 nm illumination. ${ }^{34}$

Meanwhile, the surfaces of 2D materials are free of dangling bonds, which enables them to be easily integrated with other semiconductor materials of different dimensionality, resulting in high-quality mixed-dimensional van der Waals (vdW) heterostructures. $^{35}$ The construction of mixed-dimensional vdW heterostructures has several advantages: (i) great light absorption compared with all-2D vdW heterostructures. ${ }^{13}$ (ii) More availability of component materials and a broader range of spectral selectivity ranging from UV to IR. ${ }^{36-38}$ (iii) The presence of a built-in electric field in the heterojunction can effectively accelerate the separation and transport of photo-generated carriers, leading to a fast response speed. ${ }^{39}$ (iv) More powerful and extra functions compared with the individual componentbased devices. For instance, a heterojunction photodetector with a photovoltaic effect can be operated at zero bias (selfdriven) to maximize the signal-noise ratio (SNR). ${ }^{\mathbf{4 0}}$ Therefore, the construction of the mixed-dimensional vdW heterostructures is beneficial to further improve the performance of photodetectors. On the other hand, as one of the most important semiconductor materials, silicon ( $\mathrm{Si}$ ) has been widely applied in electronic and optoelectronic devices. ${ }^{41-43} \mathrm{Si}$ nanostructures, such as Si nanowire arrays (SiNWAs), have received intensive attention in recent years due to their enhanced light absorption and excellent electron transport characteristics. ${ }^{\mathbf{1 3 , 4 4}}$ In addition, enhanced device performances have been achieved in photodetectors by using SiNWAs as the light harvesting medium. ${ }^{45}$ With these distinct properties, it is expected that the construction of a $2 \mathrm{D} \mathrm{PdSe}_{2} / \mathrm{SiNWA}$ heterojunction device may lead to a high-performance broadband photodetector.

Herein, we demonstrate, for the first time, a self-driven, polarization-sensitive, broadband photovoltaic detector by directly transferring $2 \mathrm{D} \mathrm{PdSe}{ }_{2}$ onto the top surfaces of vertically standing one-dimensional (1D) Si nanowire arrays (SiNWA). By taking advantage of the strong light confinement effect, the highquality $\mathrm{PdSe}_{2}$ /SiNWA mixed-dimensional vdW heterostructure shows apparent photovoltaic behavior under light illumination, enabling the device to work without an external power supply. Also, due to the strong infrared light absorption of multilayer $\mathrm{PdSe}_{2}$ films, the present photovoltaic detector is capable of detecting a broadband spectrum from $200 \mathrm{~nm}$ to $4.6 \mu \mathrm{m}$. Impressive device parameters in terms of a high responsivity of $726 \mathrm{~mA} \mathrm{~W}^{-1}$, a large specific detectivity of $3.19 \times 10^{14}$ Jones, a fast response speed of $25.1 / 34 \mu \mathrm{s}$, and a high polarization sensitivity of 75 are attained. Significantly, the $\mathrm{PdSe}_{2} / \mathrm{SiNWA}$ heterostructure-based photovoltaic detector can serve as a near infrared (NIR)/mid-infrared (MIR) image sensor with a well-pleasing spatial resolution. Moreover, thanks to the large surface-tovolume ratio of the $\mathrm{PdSe}_{2}$ film and SiNWA, the heterostructure device is very sensitive to relative humidity $(\mathrm{RH})$, and the lightenhanced humidity sensing properties are explored. Given these superior device characteristics, $\mathrm{PdSe}_{2} / \mathrm{SiNWA}_{\mathrm{N}}$ mixed-dimensional vdW heterostructure devices may find great potential application in optoelectronic systems and devices.

\section{Experimental details}

\section{Synthesis and characterization of $2 \mathrm{D} \mathrm{PdSe}{ }_{2}$ films and SiNWA}

2D $\mathrm{PdSe}_{2}$ films were obtained by a simple selenization method..$^{28}$ In detail, a Pd metal layer was prepared on a $\mathrm{SiO}_{2} / \mathrm{Si}$ substrate using a magnetron sputtering system. Then, the asdeposited Pd film was placed at the center zone of a tube furnace, and high-purity selenium powder (99.99\%) was put in the upstream zone. The selenium powder was heated to $240{ }^{\circ} \mathrm{C}$, and the center of the tube furnace was heated up to $480^{\circ} \mathrm{C}$ for 90 min with an $\mathrm{Ar} / \mathrm{H}_{2}(95 / 5 \mathrm{sccm})$ gas mixture. The SiNWA was synthesized via a Ag-assisted chemical etching method. ${ }^{44}$ The morphologies of $\mathrm{PdSe}_{2}$ and SiNWA were recorded by fieldemission scanning electron microscopy (FESEM, JEOL, JSM6700F) equipped with energy dispersive spectroscopy (EDS, Oxford instruments). In addition, the as-synthesized large-area $\mathrm{PdSe}_{2}$ films were characterized by using a Raman spectrometer (Horiba, LabRAM HR Evolution), an atomic force microscope (AFM, VeecoNanoscope V), an X-ray photoelectron spectrometer (XPS, Thermo ESCALAB 250) and a UV-Vis-NIR spectrophotometer (Hitachi, UH4150).

\section{Device fabrication and characterization}

To fabricate the $\mathrm{PdSe}_{2} / \mathrm{SiNWA}_{\mathrm{N}}$ heterostructure device, the 2D $\mathrm{PdSe}_{2}$ film was transferred onto the top of the SiNWA through a polymethyl methacrylate (PMMA)-assisted process. Afterwards, a Au electrode (100 nm) was deposited on the $\mathrm{PdSe}_{2}$ film as an ohmic contact to the film, and an In/Ga alloy was pasted onto the rear side of the Si substrate as the ohmic contact. The optoelectrical performances of the device were evaluated using a semiconductor parameter analyzer system (Keithley 4200-SCS, Tektronix), monochromator (Omni- $\lambda 300$, Zolix Instruments), lock-in amplifier (SR830, Stanford Research System), function generator (SDG1032X, Siglent) and an oscilloscope (DPO2012B, Tektronix) at $\sim 20 \%$ relative humidity ( $\mathrm{RH}$ ). During photoresponse measurements, a Xe lamp (Gloria-X150A, Zolix Instruments) and lasers with different wavelengths $(265 \mathrm{~nm}, 980 \mathrm{~nm}$, $2.2 \mu \mathrm{m}, 3 \mu \mathrm{m}$, and $4.6 \mu \mathrm{m}$ ) were used as light sources. For the humidity sensing study, supersaturated aqueous solutions of $\mathrm{LiCl}, \mathrm{MgCl}_{2}, \mathrm{Mg}\left(\mathrm{NO}_{3}\right)_{2}, \mathrm{NaCl}, \mathrm{KCl}$, and $\mathrm{KNO}_{3}$ were used to provide $11,33,54,75,85$ and $95 \% \mathrm{RH}$ at room temperature, respectively.

\section{Theoretical calculations}

The electric field energy density distribution of the device was simulated by the FDTD method. The refractive index of $c$-silicon 
reported by Palik was used. ${ }^{46}$ Due to the large difference in both the real and imaginary part of the $c$-silicon refractive index over the wavelength range from $200-2000 \mathrm{~nm}$, it is very difficult to fit the optical index in the whole range in a single simulation. So the simulations were divided into two regions for better fitting with a smaller fitting error (200-800 $\mathrm{nm}$ and 800-2000 $\mathrm{nm})$. To reduce the memory requirements of a simulation, the thickness of bulk silicon is set as $50 \mu \mathrm{m}$, much less than that of a real silicon wafer. As a result, the obtained simulated absorption spectra have notable differences compared to the experimental results around the absorption edge. For SiNWA simulation, according to the NW diameter distribution shown in Fig. 1h, the final absorption spectrum of the SiNWA was obtained by averaging the results of NWs with diameters of $100 \mathrm{~nm}, 120 \mathrm{~nm}, 140$ $\mathrm{nm}, 160 \mathrm{~nm}, 180 \mathrm{~nm}$, and $200 \mathrm{~nm}$ with a period of $80 \mathrm{~nm}$.

\section{Results and discussion}

In this work, large-area $\mathrm{PdSe}_{2}$ films were grown by a straightforward selenization process on $\mathrm{SiO}_{2} / \mathrm{Si}$ substrates at a relatively low temperature. After the transformation of the precursor Pd layer into 2D layered $\mathrm{PdSe}_{2}$, an obvious color change from blue to dark green can be observed, as shown in Fig. 1a. With the availability of large-area and continuous $\mathrm{PdSe}_{2}$ films, the sample was further characterized by Raman spectroscopy. In Fig. 1b, Raman spectra acquired from five randomly selected positions in Fig. 1a show four obvious peaks at $\sim 144 \mathrm{~cm}^{-1}$, $\sim 205 \mathrm{~cm}^{-1}, \sim 222 \mathrm{~cm}^{-1}$, and $\sim 256 \mathrm{~cm}^{-1}$ due to $\mathrm{A}_{\mathrm{g}}^{1}, \mathrm{~A}_{\mathrm{g}}^{2}$, and $\mathrm{B}_{1 \mathrm{~g}}$ active modes and $\mathrm{A}_{\mathrm{g}}^{3}$ vibration mode with excellent consistency, suggesting the good uniformity and homogeneity of the largearea 2D $\mathrm{PdSe}_{2}$ films. Fig. 1c shows an AFM image of the $\mathrm{PdSe}_{2}$ film, revealing a multilayer structure of the as-synthesized $\mathrm{PdSe}_{2}$ film with a thickness of $\sim 18.9 \mathrm{~nm}$. In addition, the chemical composition of the as-grown $\mathrm{PdSe}_{2}$ film was further confirmed by XPS characterization. Fig. 1d shows the typical deconvoluted XPS results for Pd $3 d$ and Se $3 d$ of the PdSe $\mathrm{P}_{2}$ film. The Pd 3d can be deconvoluted into two peaks at 336.8 and 342 $\mathrm{eV}$ assigned to $\mathrm{Pd} 3 \mathrm{~d}_{5 / 2}$ and $\mathrm{Pd} 3 \mathrm{~d}_{3 / 2}$, respectively. The Se $3 \mathrm{~d}$ can be deconvoluted into two peaks at 54.8 and $55.6 \mathrm{eV}$, which correspond to Se $3 d_{5 / 2}$ and Se $3 d_{3 / 2}$ orbitals, respectively. By quantifying the peaks, the atomic ratio of $\mathrm{Pd} / \mathrm{Se}$ was determined to be $\sim 1: 2$. Furthermore, the FESEM image of the $\mathrm{PdSe}_{2}$ film on the Si substrate indicates that the film is continuous and uniform with a smooth surface (Fig. S1a†). Elemental mapping
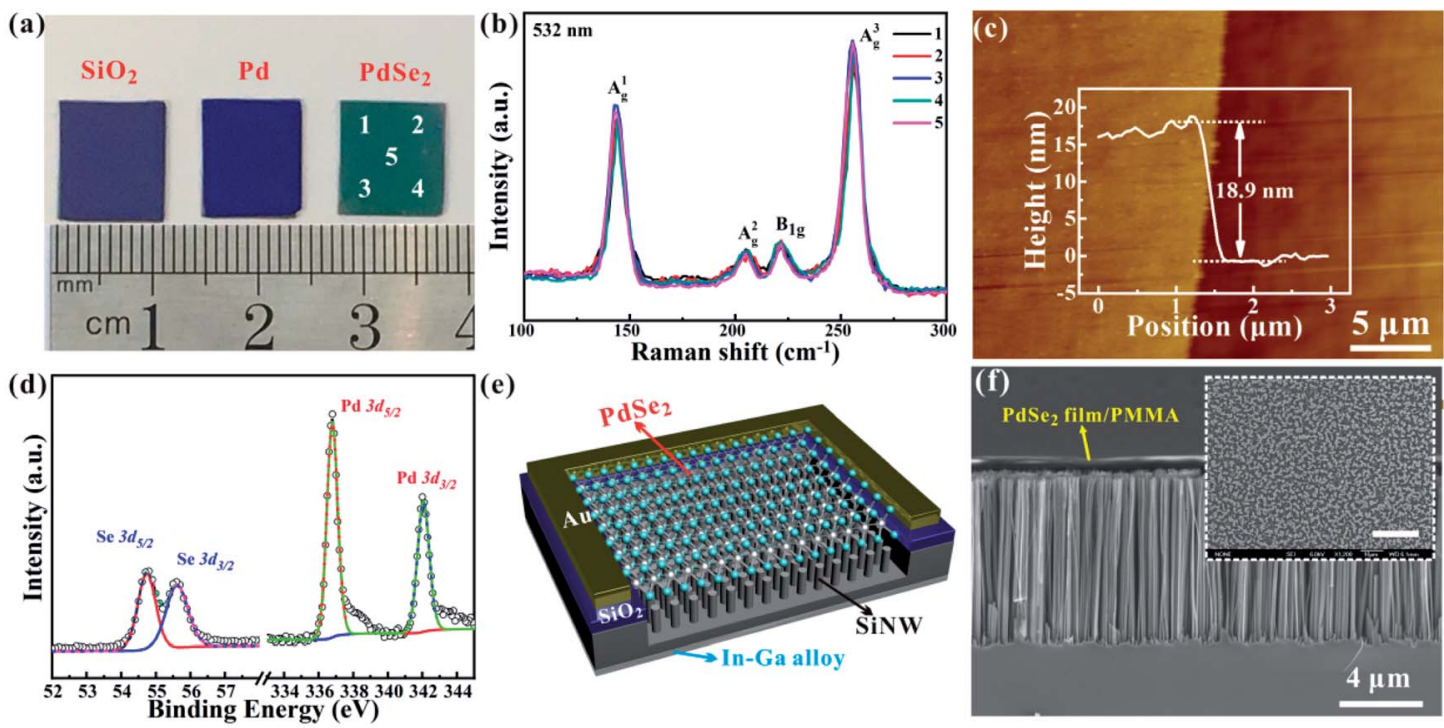

(e)
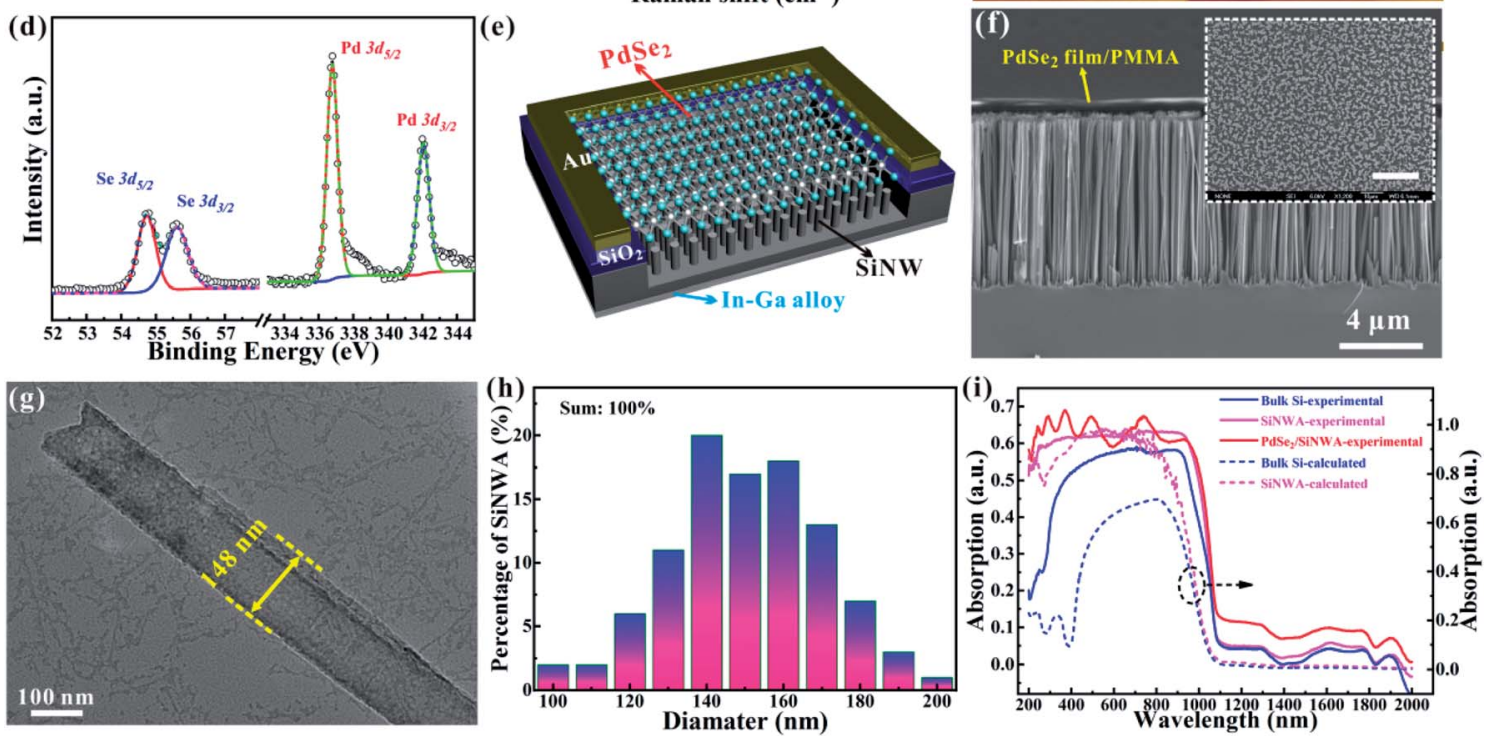

Fig. 1 (a) Photograph of the PdSe film fabricated on the $\mathrm{SiO}_{2} / \mathrm{Si}$ substrate. (b) Raman spectra of the 2D PdSe film acquired from different points marked in (a). (c) AFM image of the PdSe $e_{2}$ film with the height profile. (d) XPS spectra of the PdSe $e_{2}$ film, showing the binding energies of Pd $3 d$ and $\mathrm{Se} 3 \mathrm{~d}$ peaks. (e) Schematic diagram of the $\mathrm{PdS} \mathrm{e}_{2} / \mathrm{SiNWA}$ mixed-dimensional vdW heterostructure device. (f) Cross-sectional SEM image of the $\mathrm{PdSe}_{2} / \mathrm{SiNWA}$ heterostructure. The inset shows the top-view image of the heterostructure. The scale bar in the inset is $20 \mu \mathrm{m}$. (g) TEM image of a single SiNW. (h) Statistical distribution of the diameters of SiNWs. (i) Absorption spectra of the SiNWA, bulk $\mathrm{Si}_{\text {and PdSe }} / \mathrm{SiNWA}_{\mathrm{N}}$ heterostructure (solid line). The theoretically calculated absorption spectra of the bulk Si and SiNWA are also demonstrated (dashed line). 
in a randomly selected area also demonstrates that both Pd and Se elements are uniformly distributed over the observed zone (Fig. S1b and $\mathrm{c} \dagger$ ).

Fig. 1e shows the schematic diagram of the photovoltaic detector based on the $\mathrm{PdSe}_{2} / \mathrm{SiNWA}$ mixed-dimensional vdW heterostructure. The detailed fabrication process and the photograph of an assembled device could be found in Fig. S2 and $\mathrm{S} 3, \dagger$ respectively. From the cross-sectional SEM image of the $\mathrm{PdSe}_{2}$ /SiNWA heterostructure device (Fig. 1f), we note that the $\mathrm{PdSe}_{2}$ film was fully supported by the vertically aligned SiNWA. The length of the SiNW is about $8 \mu \mathrm{m}$, while the diameter of a representative $\mathrm{Si}$ nanowire (NW) is $\sim 148 \mathrm{~nm}$ (Fig. 1g). According to the statistical distribution shown in Fig. 1h, the diameter of the NWs is determined to be in the range of $100-200 \mathrm{~nm}$, with an average value of $\sim 150 \mathrm{~nm}$.
Furthermore, we systemically compared the absorption spectra of the bulk $\mathrm{Si}$, the SiNWA and the PdSe ${ }_{2} / \mathrm{SiNWA}_{\mathrm{N}}$ hbrid system. Note that the SiNWA displays enhanced light absorption in the entire region compared to the bulk $\mathrm{Si}$, which is consistent with the theoretical calculation based on finite-difference time domain (FDTD) simulations. More importantly, by depositing the 2D $\mathrm{PdSe}_{2}$ film on the top surface of the SiNWA, the light absorption of the $\mathrm{PdSe}_{2} / \mathrm{SiNWA}$ hybrid system is further enhanced and extended beyond $1100 \mathrm{~nm}$ due to the broadband absorption of the 2D $\mathrm{PdSe}_{2}$ film.

Fig. 2a presents the current-voltage $(I-V)$ curves of the $\mathrm{PdSe}_{2} /$ SiNWA heterostructure measured in the dark (black curves) and under light illumination (colored curves). Notably, a remarkable current rectifying characteristic with a rectification ratio of over $10^{2}$ within $\pm 5 \mathrm{~V}$ was observed, revealing the high-quality of the
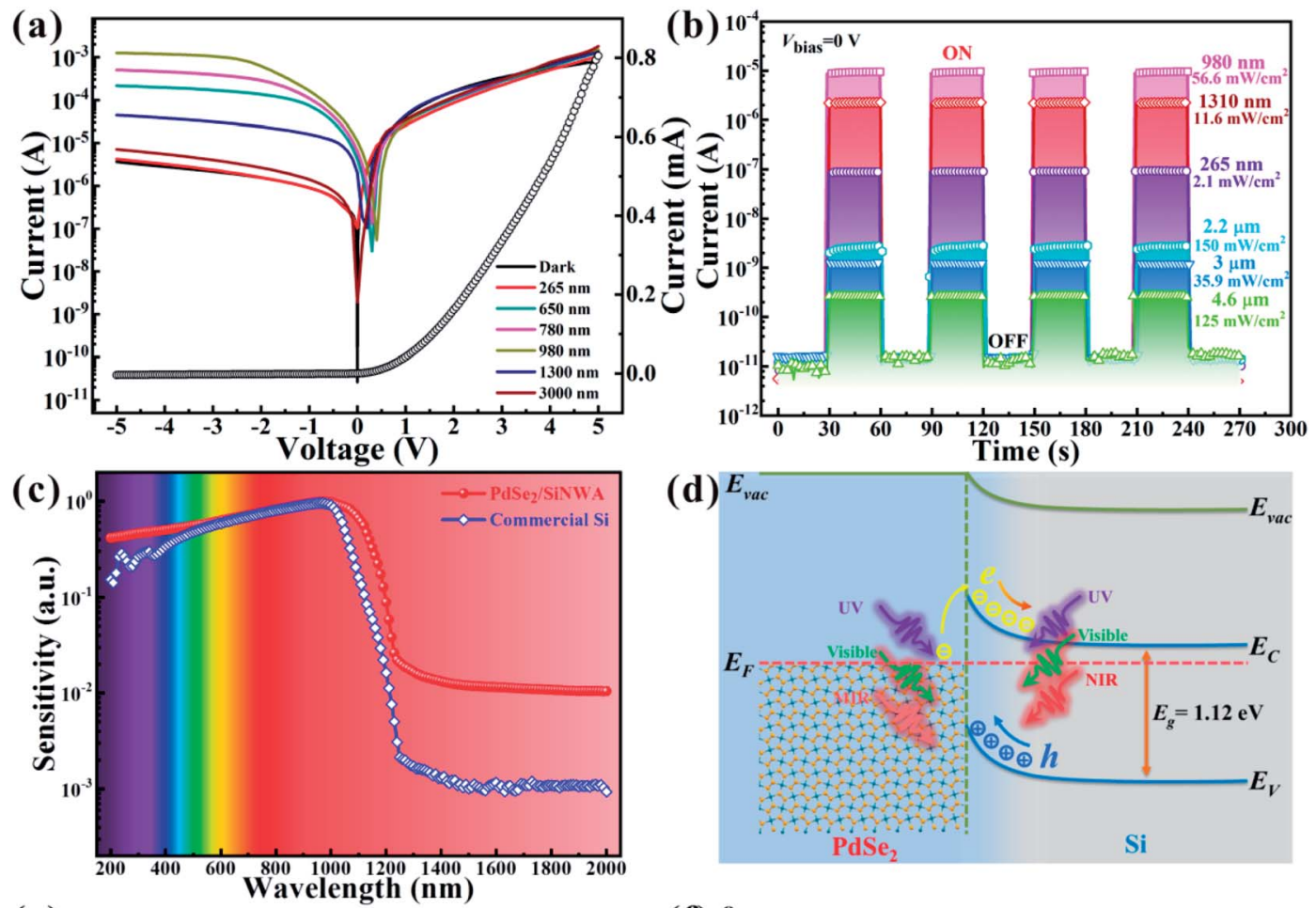

(d) $E_{\text {vac }}$
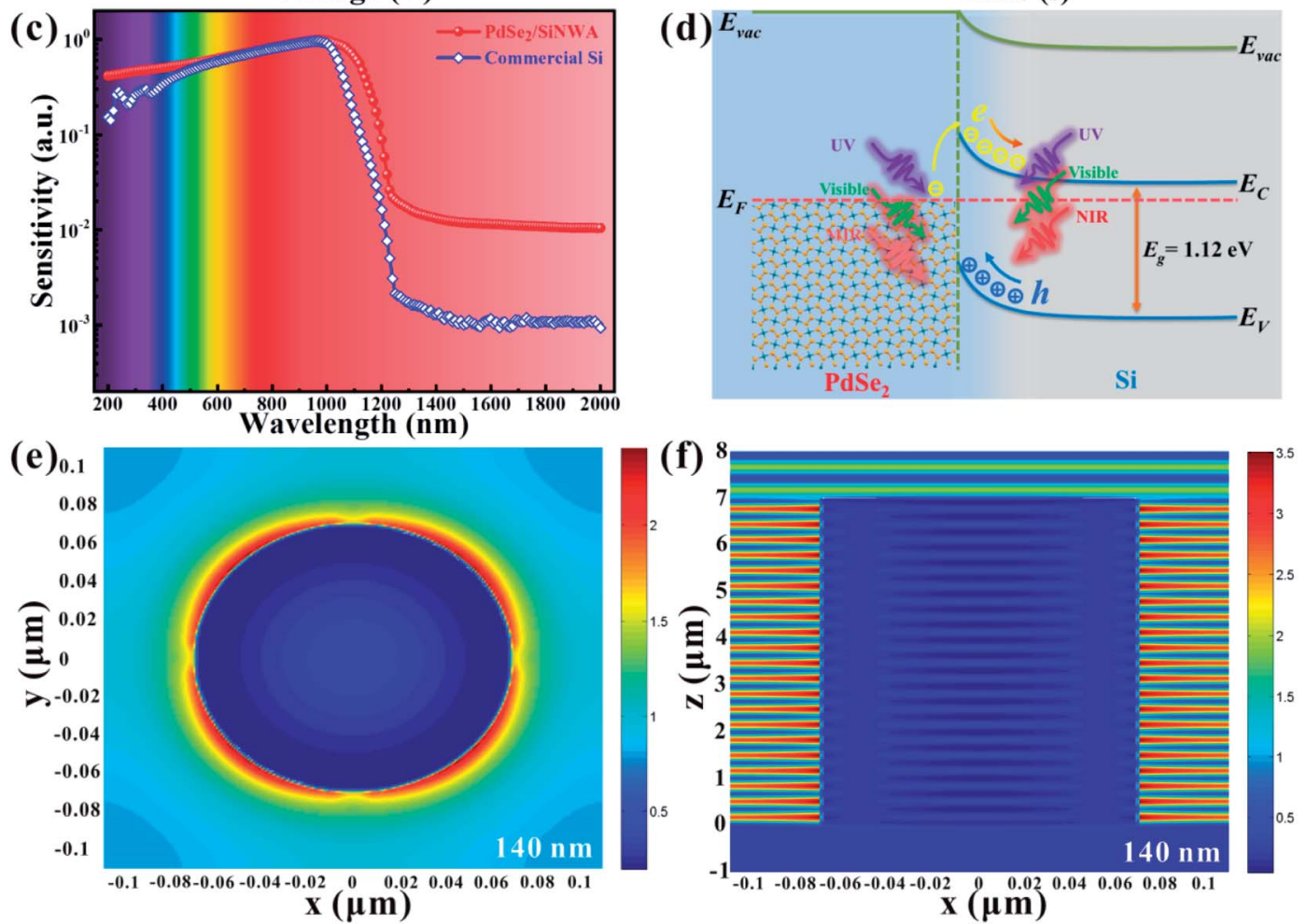

Fig. 2 (a) $I-V$ curves and (b) time-resolved photoresponse properties of a $\mathrm{PdSe} \mathrm{S}_{2} / \mathrm{SiNWA}$ heterostructure device under light illumination with

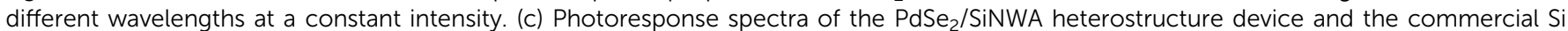
photodetector (DSi200, Zolix). (d) Energy band diagram of the PdSe $2 / S i N W A$ heterostructure under light illumination. (e and f) Simulated electric field energy distribution for the PdSe $2 / \mathrm{SiNWA}$ with a diameter of $140 \mathrm{~nm}$. 
$\mathrm{PdSe}_{2} / \mathrm{SiNWA}$ heterostructure. Au and In/Ga alloys were used as the electrodes in the device, which showed good ohmic contacts with $\mathrm{PdSe}_{2}$ and $\mathrm{Si}$, respectively (Fig. $\mathrm{S} 4 \dagger$ ). Hence, the diode characteristics of the device could be attributed to the forma-

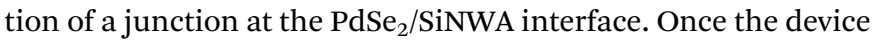
was illuminated using light signals, obvious photoresponse behavior was observed in the reverse bias direction. Careful examination also revealed that the device displayed pronounced photovoltaic behavior in a wide wavelength range, making the present device a broadband and self-driven photovoltaic detector. Fig. $2 \mathrm{~b}$ presents the time-resolved photoresponse of the $\mathrm{PdSe}_{2} / \mathrm{SiNWA}_{\mathrm{N}}$ heterostructure photovoltaic detector at zero bias in a broad spectrum ranging from deep ultraviolet (DUV) to MIR. The photovoltaic detector shows stable, repeatable and fast response to incident light with current on/off ratios $\left(I_{\text {on }} / I_{\text {off }}\right)$ of $10^{4}$ for $265 \mathrm{~nm}\left(2.1 \mathrm{~mW} \mathrm{~cm}{ }^{-2}\right), 10^{6}$ for $980 \mathrm{~nm}(56.6 \mathrm{~mW}$ $\left.\mathrm{cm}^{-2}\right), 10^{2}$ for $2.2 \mu \mathrm{m}\left(150 \mathrm{~mW} \mathrm{~cm}{ }^{-2}\right)$ and $3 \mu \mathrm{m}(35.9 \mathrm{~mW}$ $\left.\mathrm{cm}^{-2}\right)$, and 26 for $4.6 \mu \mathrm{m}\left(125 \mathrm{~mW} \mathrm{~cm}^{-2}\right)$. Note that the $\mathrm{PdSe}_{2} /$ SiNWA heterostructure photovoltaic detectors with a capability of detecting MIR signals at room temperature (RT) are potentially significant for remote sensing, night vision, imaging sensors, and so on. ${ }^{47}$ Fig. $2 \mathrm{c}$ shows the spectral response of the $\mathrm{PdSe}_{2} / \mathrm{SiNWA}$ heterostructure photovoltaic detector under constant power intensity. The devices exhibit a broadband response from $200 \mathrm{~nm}$ to $2000 \mathrm{~nm}$ (limited by the measurement instrument) with the highest sensitivity being around $980 \mathrm{~nm}$ because of the strong absorption of the SiNW (see the plotted spectral response curve of a commercial Si photodetector, DSi200 Zolix). However, in contrast to the commercial Si photodetector, the $\mathrm{PdSe}_{2} / \mathrm{SiNWA}$ heterostructure photovoltaic detector has a higher sensitivity in both UV and NIR regions due to the enhanced light absorption of the hybrid $\mathrm{PdSe}_{2} / \mathrm{SiNWA}$ system. The broadband photodetection performance of the $\mathrm{PdSe}_{2} / \mathrm{SiNWA}$ heterostructure device can be understood using the energy band diagram, as illustrated in Fig. 2d. Due to the semimetallic nature of the multilayer $\operatorname{PdSe}_{2}$ films, a Schottky contact will be formed between the PdSe $_{2}$ film and the SiNWA. ${ }^{37}$ As a consequence, the difference in their Fermi levels will lead to the generation of a built-in potential in the depletion region. When the device is illuminated by light with photon energy larger than the bandgap of $\mathrm{Si}(1.12 \mathrm{eV})$, both the $\mathrm{PdSe}_{2}$ film and the SiNWA will absorb the light, resulting in an increase of the photocurrent. On the other hand, if the photon energy of the incident light is lower than $1.12 \mathrm{eV}$, only the $\mathrm{PdSe}_{2}$ films can absorb the light. This enables the electrons in the $\mathrm{PdSe}_{2}$ films to cross over the Schottky barrier at the junction interface, contributing to the photoresponse in the MIR range.

To shed light on the excellent photoresponse properties of the photovoltaic detector, simulations of electric field energy density distribution of the devices were performed using FDTD simulations. Fig. 2e and f present the electric field energy distribution of the $\mathrm{PdSe}_{2} / \mathrm{SiNWA}$ heterostructure with a NW diameter of $140 \mathrm{~nm}$ under $980 \mathrm{~nm}$ unpolarized light. And the electric field energy distributions for the NWs with different sizes are shown in Fig. S5. $\dagger$ It can be observed that the incident light is mainly trapped in gaps between the NWs. In particular, the electric field is greatly enhanced at the side surfaces of NWs.
One can thus expect significant absorption enhancement because the overall area of side surfaces of NWs is much larger than that of the single surface of bulk silicon.

The photoresponse properties of the $\mathrm{PdSe}_{2} / \mathrm{SiNWA}_{\mathrm{N}}$ heterostructure device are strongly dependent on the power intensity of incident light. Fig. 3a shows the $I-V$ curves of the photovoltaic detector measured under $980 \mathrm{~nm}$ light with different intensities. It is noted that the current at reverse bias increases gradually with the increasing light intensity from 0.07 to $56.6 \mathrm{~mW}$ $\mathrm{cm}^{-2}$. A maximum open-circuit voltage $\left(V_{\mathrm{OC}}\right)$ of $0.26 \mathrm{~V}$ and a short-circuit current $\left(I_{\mathrm{SC}}\right)$ of $7.5 \mu \mathrm{A}$ are achieved at a power intensity of $56.6 \mathrm{~mW} \mathrm{~cm} \mathrm{~cm}^{-2}$ (Fig. S6†). Even though the power conversion efficiency of the device is not so high $(\sim 0.1 \%)$, it is high enough to enable the device to operate at zero bias without an external power supply. Moreover, the low dark current at zero bias leads to an $I_{\text {on }} / I_{\text {off }}$ as high as $10^{6}$ at $56.6 \mathrm{~mW} \mathrm{~cm}^{-2}$ with excellent stability and reproducibility (Fig. $3 \mathrm{~b}$ ), which is much larger than the value of the $\operatorname{SiNWA}(\sim 1.1$, Fig. S7 $\dagger)$. The $I_{\text {on }} / I_{\text {off }}$ is 34.3 even at an ultralow light intensity of $27.5 \mathrm{nW} \mathrm{cm} \mathrm{cm}^{-2}$. This result demonstrates the high sensitivity of the $\mathrm{PdSe}_{2} / \mathrm{SiNWA}$ heterostructure photovoltaic detector with the capability of detecting ultraweak light signals. As a matter of fact, the dependence of extracted photocurrent on power intensity can be described by the power law: $I=A P^{\alpha}$, where the exponent $\alpha$ represents the recombination of photoexcited carriers. ${ }^{48}$ By fitting the data in a relatively low light intensity range (Fig. 3c), an ideal exponent of $\alpha \approx 1.0$ was obtained, while a non-ideal value of 0.38 was obtained in a high light intensity region. The value is less than one at a higher light intensity due to the enhanced recombination loss and the existence of trap states at the junction interface. ${ }^{6,49}$ In addition, the linear dynamic range (LDR) of a photodetector is the maximum linear response relative to its noise, which can be given by the following formula: ${ }^{36}$

$$
\mathrm{LDR}=20 \log \frac{I_{\mathrm{ph}}^{*}}{I_{\mathrm{D}}}
$$

where $I_{\mathrm{ph}}^{*}$ is the photocurrent measured at a light intensity of 1 $\mathrm{mW} \mathrm{cm}{ }^{-2}$, and $I_{\mathrm{D}}$ is the dark current at zero bias (Fig. S8 $\dagger$ ). A large LDR of $108.3 \mathrm{~dB}$ was calculated at zero bias, which is comparable with that of a commercial Si photodetector $(\sim 120$ $\mathrm{dB})^{50}$ and superior to that of some $2 \mathrm{D} / \mathrm{Si}$ heterojunction devices (42-92 dB), ${ }^{\mathbf{4 4 , 4 5 , 5 1}}$ commercial InGaAs photodiodes (66 dB), ${ }^{47}$ and all-graphene $\mathrm{p}-\mathrm{n}$ heterojunction devices $(93 \mathrm{~dB}) .{ }^{52}$ Such an excellent photoresponse performance is reasonably ascribed to the enhanced light absorption characteristics of the $\mathrm{PdSe}_{2} /$ SiNWA heterostructure.

As the key figures of merit for a photodetector, responsivity $(R)$ and specific detectivity $\left(D^{*}\right)$ can be evaluated using the following formulas: ${ }^{53}$

$$
\begin{gathered}
R=\frac{I_{\mathrm{ph}}}{P_{\text {in }} S} \\
D^{*}=\sqrt{\frac{A}{2 e I_{\mathrm{D}}}} R
\end{gathered}
$$



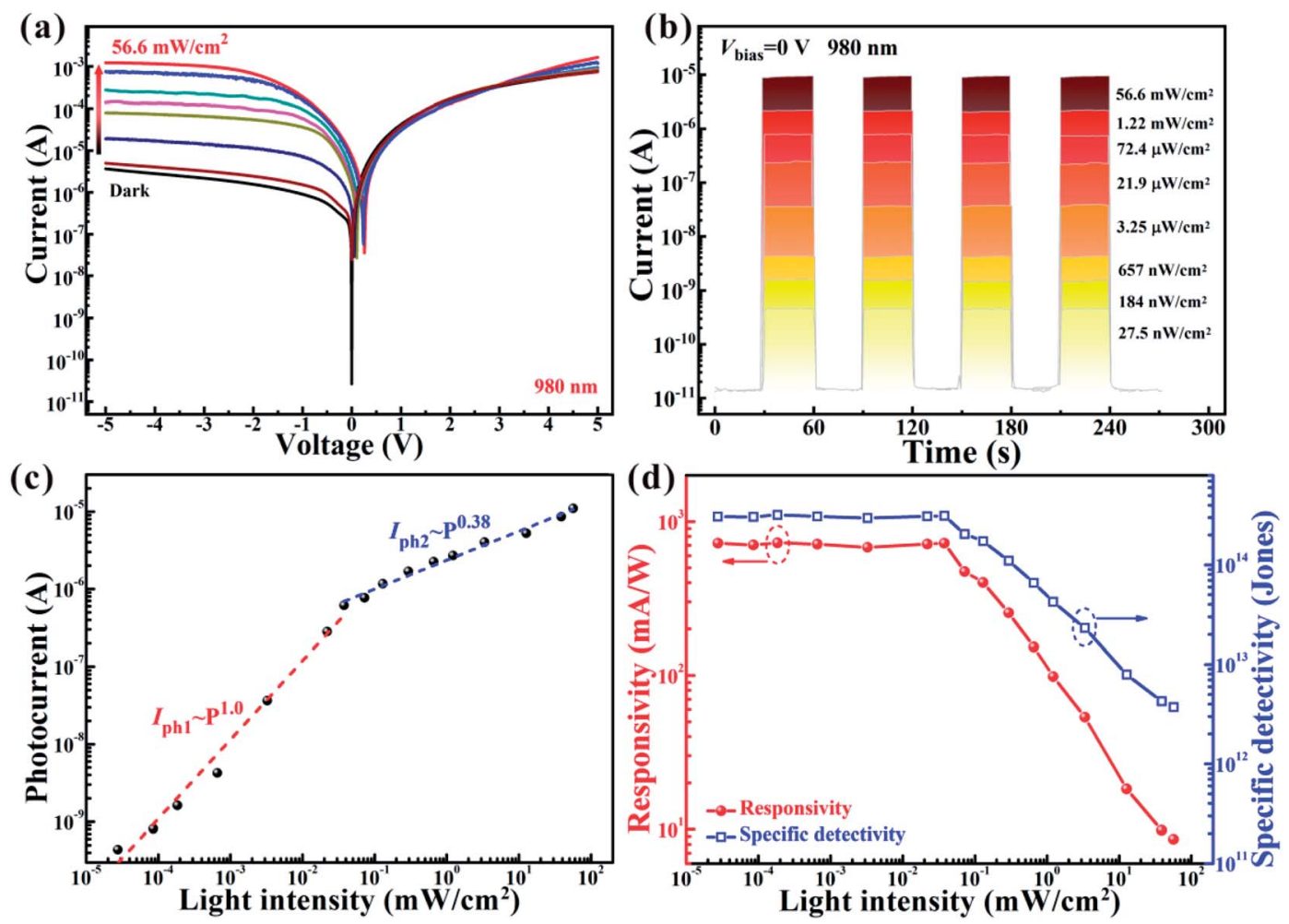

Fig. 3 (a) I-V curves and (b) time-resolved photoresponse of the $\mathrm{PdSe}_{2} / \mathrm{SiNWA}$ photodetector under $980 \mathrm{~nm}$ light illumination with varied light intensity. (c) Logarithmic plot of the photocurrent versus light intensity. (d) Responsivity and specific detectivity of the heterostructure photodetector as a function of light intensity.

where $P_{\text {in }}, S, A$, and $e$ are the light intensity, illumination area, device area, and unit charge, respectively. According to the above formulas, $R$ and $D^{*}$ versus light intensity were calculated, as plotted in Fig. 3d. With the reduction of light intensity from $56.6 \mathrm{~mW} \mathrm{~cm}^{-2}$ to $27.5 \mathrm{nW} \mathrm{cm}{ }^{-2}$, both $R$ and $D^{*}$ were found to increase gradually. Notably, the saturated $R$ and $D^{*}$ values with maximum values of $726 \mathrm{~mA} \mathrm{~W} \mathrm{~W}^{-1}$ and $3.19 \times 10^{14} \mathrm{~cm} \mathrm{~Hz}^{1 / 2} \mathrm{~W}^{-1}$ (Jones) were observed in the low light intensity region, manifesting that this photovoltaic detector can show a linear response to weak light signals.

Response speed is another significant parameter for evaluating the ability of a photodetector to follow a rapidly varying optical signal, which can be characterized by calculating the time interval between $10 \%$ (or $90 \%$ ) and $90 \%$ (or $10 \%$ ) of the maximum photocurrent at the rising/falling edge. Fig. 4a depicts the time-resolved photoresponse of the device to 980 $\mathrm{nm}$ pulsed light at frequencies of 1,2 and $5 \mathrm{kHz}$, respectively, with a normalized photocurrent, showing fast and stable responses to pulsed light signals. From the relative balance $\left[\left(I_{\max }-I_{\min }\right) / I_{\max }\right]$ shown in Fig. $4 \mathrm{~b}$, it is clear that the device can respond to a fast switching light signal of up to $10^{5} \mathrm{~Hz}$, and possesses a high $3 \mathrm{~dB}$ frequency $\left(f_{3 \mathrm{~dB}}\right)$ of $\sim 8 \mathrm{kHz}$. By further analysis of each of the edges of response, the response speeds of

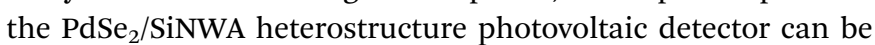

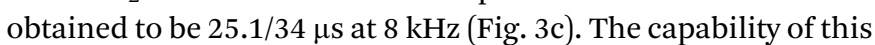
photovoltaic detector to follow a rapidly varied pulsed signal was further investigated by using a pulsed laser light of $266 \mathrm{~nm}$ at $1 \mathrm{kHz}$ with a pulse width of $1 \mathrm{~ns}$. In Fig. $4 \mathrm{~d}$ and e, each pulse signal can be well identified with an ultrafast rising time of 126 ns, revealing the capability of the device to detect nanosecond pulsed light signals. Significantly, the comprehensive performance of the $\mathrm{PdSe}_{2} / \mathrm{SiNWA}_{\text {heterostructure photovoltaic }}$ detector is superior to that of recently reported 2D layered material-based infrared photodetectors, as summarized in Table 1.

In addition to these impressive photoresponse characteristics, the $\mathrm{PdSe}_{2} / \mathrm{SiNWA}_{\mathrm{N}}$ heterostructure-based device also shows very high sensitivity to polarized light signals, which originates from the pentagonally arranged asymmetric crystal structure of $\mathrm{PdSe}_{2}$ with a puckered morphology. ${ }^{31}$ Fig. 5a shows a schematic diagram of the experimental setup based on the present $\mathrm{PdSe}_{2} /$ SiNWA device. A polarizer can turn an incident light into a polarized light, and the polarization angle can be adjusted by using a half-wave plate. The polarization angle-dependent photocurrent is plotted in Fig. 5b, which has been normalized according to the minimum value. From the measured photocurrent at zero bias, the photocurrent is found to reach a maximum value at $0^{\circ}\left(180^{\circ}\right)$, while a minimum value is obtained at $90^{\circ}\left(270^{\circ}\right)$, giving rise to a high polarization sensitivity of 75 . It is noteworthy that this value is much larger than that obtained for other 2D layered material-based devices, such as $\mathrm{GeS}_{2}(2.1)^{54}$ and black phosphorus/MoS $(22){ }^{55}$ revealing the great potential of the photodetector for obtaining polarimetric information, high-contrast polarizers and optical switch 

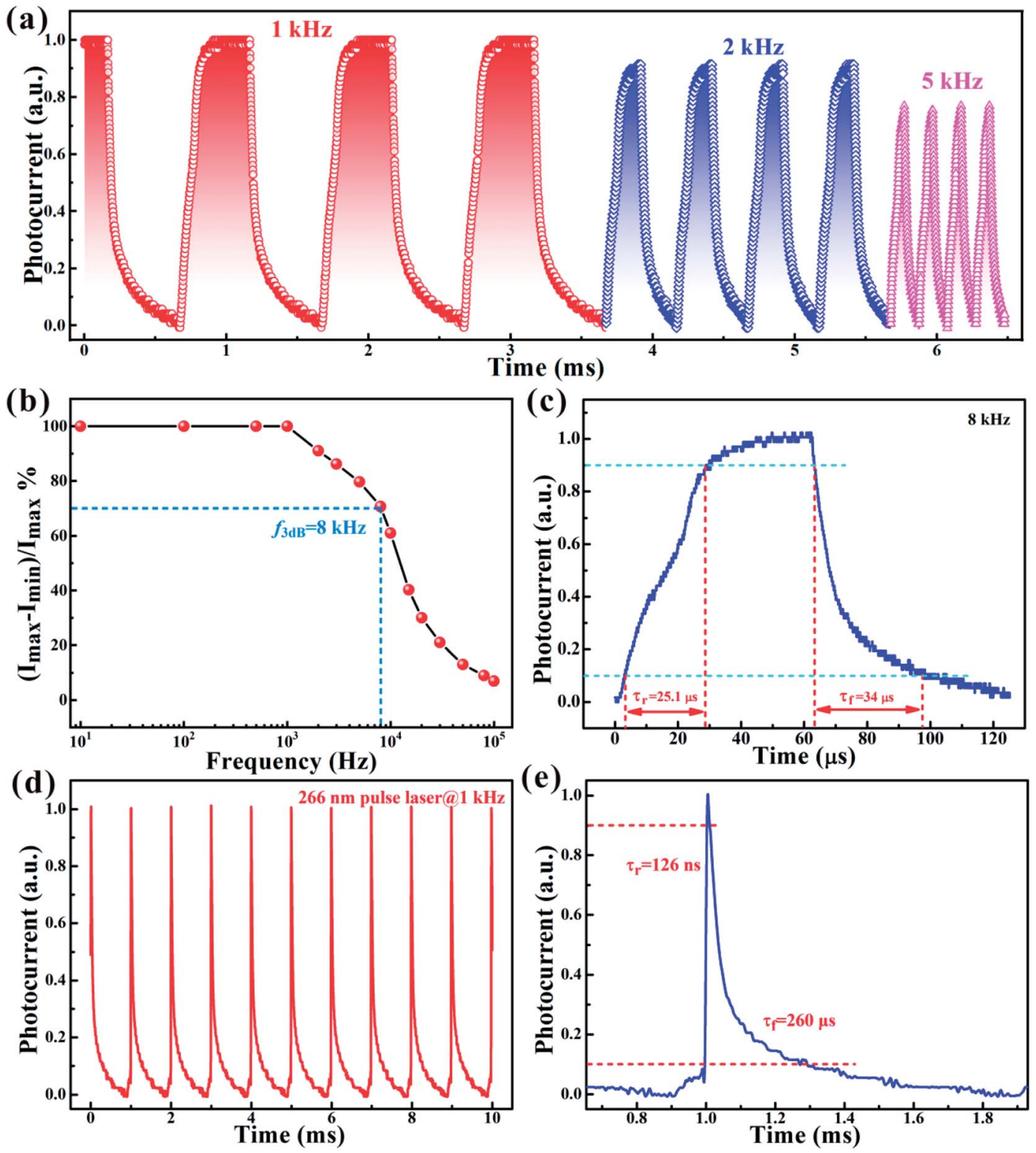

Fig. 4 (a) Time-resolved photoresponses of the PdSe $/ 2$ SiNWA heterostructure to $980 \mathrm{~nm}$ pulsed light with frequencies of 1,2 and $5 \mathrm{kHz}$, respectively. (b) Relative balance $\left[\left(I_{\max }-I_{\min }\right) / I_{\max }\right]$ as a function of switching frequency. (c) Response speeds at $8 \mathrm{kHz}$. (d) The photoresponse of the heterostructure device to $266 \mathrm{~nm}$ pulsed laser light at $1 \mathrm{kHz}$ with a pulse width of $1 \mathrm{~ns}$. (e) An enlarged response cycle for evaluating the response speed.

applications. ${ }^{56}$ The highly polarization-sensitive photodetection performance of the $\mathrm{PdSe}_{2} / \mathrm{SiNWA}_{\mathrm{N}}$ heterojunction could be attributed to the following reasons. First, the high asymmetry of the $2 \mathrm{D} \mathrm{PdSe}_{2}$ films leads to strong anisotropic properties. ${ }^{31}$ Second, the low dark current of the heterojunction at zero bias is beneficial to improve the polarization sensitivity. ${ }^{57}$ Third, the

Table 1 Comparison of the performances of the $\mathrm{PdSe}_{2} / \mathrm{SiNWA}$ heterojunction photodetector with some reported photodetectors

\begin{tabular}{llllll}
\hline Devices & $\lambda[\mu \mathrm{m}]$ & $I_{\text {on }} / I_{\text {off }}$ & $R\left[\mathrm{~mA} \mathrm{~W}^{-1}\right]$ & $D^{*}[$ Jones $]$ & Response speed $[\mu \mathrm{s}]$ \\
\hline $\mathrm{PdSe}_{2} / \mathrm{SiNWA}$ & $0.2-4.6$ & $10^{6}$ & 726 & $3.19 \times 10^{14}$ & $3.4 / 3.9(100 \mathrm{kHz})$ \\
$\mathrm{PdSe}_{2} / \mathrm{Si}$ & $0.2-3$ & $\sim 10^{5}$ & 300 & $\sim 10^{13}$ & $38 / 44(5 \mathrm{kHz})$ \\
$\mathrm{PdSe}_{2} / \mathrm{Ge}$ & $0.2-3$ & $10^{5}$ & 691 & $1.73 \times 10^{13}$ & $6.4 / 92.5(5 \mathrm{kHz})$ \\
$\mathrm{PdSe}_{2} / \mathrm{GeNCA}$ & $0.2-2.2$ & $<10^{4}$ & 530 & $1.45 \times 10^{11}$ & $25.4 / 38.5(20 \mathrm{kHz})$ \\
$\mathrm{PdSe}_{2} / \mathrm{MoS}_{2}$ & $0.45-10.6$ & $\sim 10^{4}$ & 185.6 & $1.73 \times 10^{13}$ & $65.3 / 62.4(1 \mathrm{kHz})$ \\
$\mathrm{PtSe}_{2} / \mathrm{SiNWA}_{\mathrm{SOS}_{2} / \mathrm{SiNWA}}$ & $0.2-1.55$ & $\sim 10^{4}$ & 18.4 & $3.26 \times 10^{11}$ & $10.1 / 19.5(10 \mathrm{kHz})$ \\
$\mathrm{MSH}_{2}$ & $\sim 10^{5}$ & 298 & $2.8 \times 10^{13}$ & $2.9 / 7.3(50 \mathrm{kHz})$
\end{tabular}


(a)

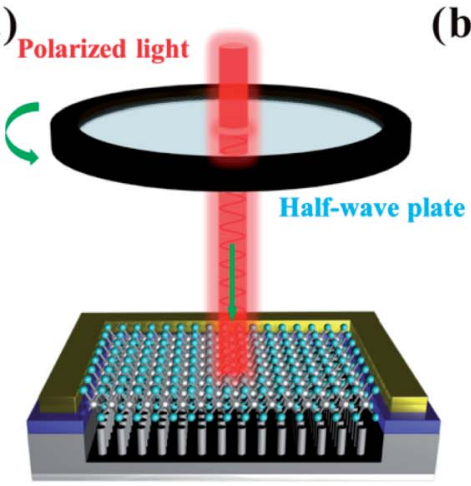

(b)

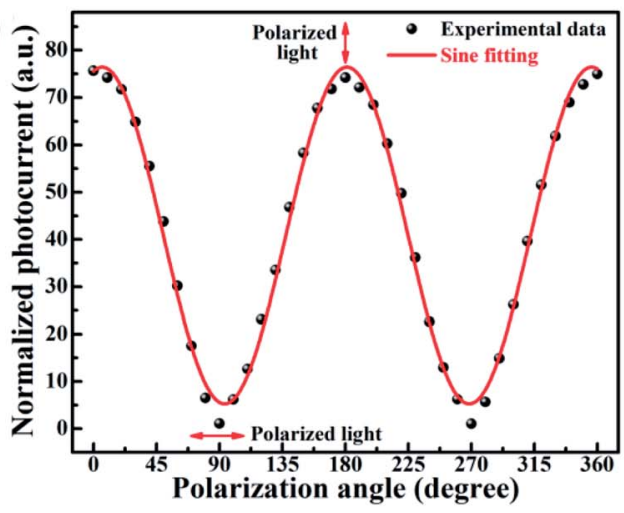

(c)

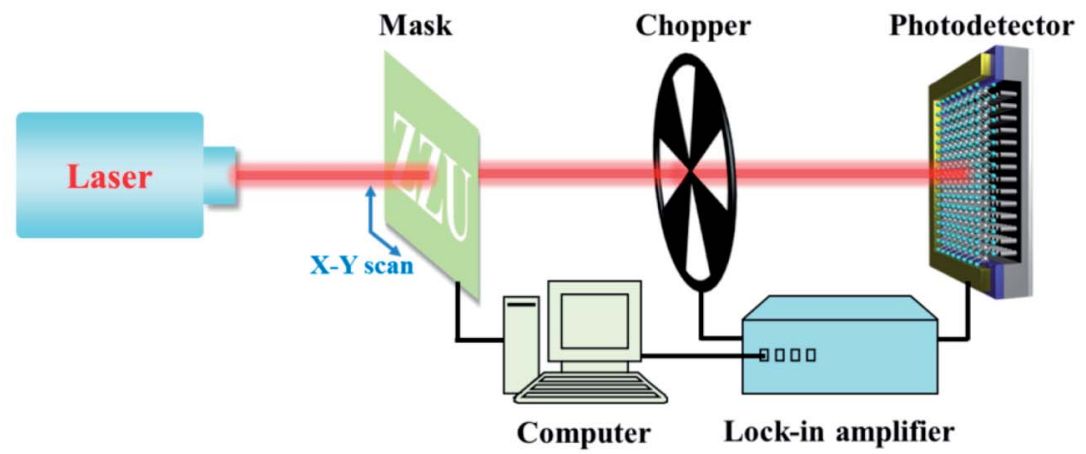

(d)

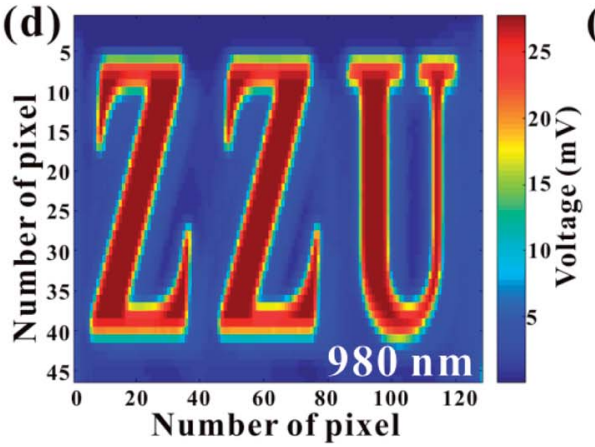

(e)

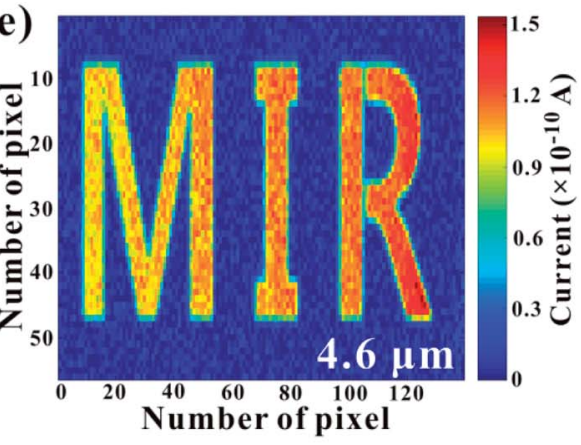

Fig. 5 (a) Schematic diagram of the experimental setup for polarization sensitivity measurement. (b) Normalized photocurrent of the heterostructure as a function of the polarization angle. (c) Schematic illustration of the measurement setup for imaging application. The imaging results of the (d) "ZZU" pattern under $980 \mathrm{~nm}$ illumination and (e) "MIR" pattern under $4.6 \mu \mathrm{m}$ illumination, respectively.

built-in perpendicular electric field in the vertical heterojunction can effectively and quickly separate the photogenerated carriers, and reduce the carrier recombination during charge transport. ${ }^{13}$

As one of the most important functionalities of photodetectors, the imaging ability of photodetectors has attracted tremendous interest due to their great importance in both civilian and military fields. ${ }^{58,59}$ In view of the outstanding photoresponse capability of the $\mathrm{PdSe}_{2} / \mathrm{SiNWA}$ heterostructure photovoltaic detector, the infrared image sensing ability of the current device was further explored. Fig. $5 \mathrm{c}$ displays a schematic diagram of the measurement setup for an imaging sensor, in which lasers of $980 \mathrm{~nm}$ and $4.6 \mu \mathrm{m}$ were used to provide infrared signals, and metal masks with hollow "ZZU" and "MIR" patterns fixed on a $2 \mathrm{D}$ motorized stage were placed between the light sources and detector. During the image-sensing process, the electrical signals (voltage or current) of the $\mathrm{PdSe}_{2} / \mathrm{SiNWA}$ heterostructure photovoltaic detector were collected by using a lock-in amplifier, and then the apparent 2D contrast mapping images of the "ZZU" pattern for $980 \mathrm{~nm}$ and the "MIR" pattern for $4.6 \mu \mathrm{m}$ (Fig. $5 \mathrm{~d}$ and e) were generated. It should be pointed out that high-resolution imaging results with a voltage contrast ratio of over $10^{3}$ for $980 \mathrm{~nm}$ and a current contrast ratio of over $10^{2}$ for $4.6 \mu \mathrm{m}$ were obtained, verifying the excellent infrared imaging capability of the as-assembled $\mathrm{PdSe}_{2} / \mathrm{SiNWA}$ photovoltaic detector.

Due to the large surface-to-volume ratio of both the 2D PdSe ${ }_{2}$ film and the SiNWA, the $\mathrm{PdSe}_{2} / \mathrm{SiNWA}_{\mathrm{N}}$ heterostructure device shows high sensitivity to the relative humidity $(\mathrm{RH})$ of the surrounding atmosphere. In this work, we further explored the humidity sensing properties of the device. Fig. $6 \mathrm{a}$ and $\mathrm{b}$ show the response properties of the $\mathrm{PdSe}_{2} / \mathrm{SiNWA}_{\text {heterostructure to }}$ 

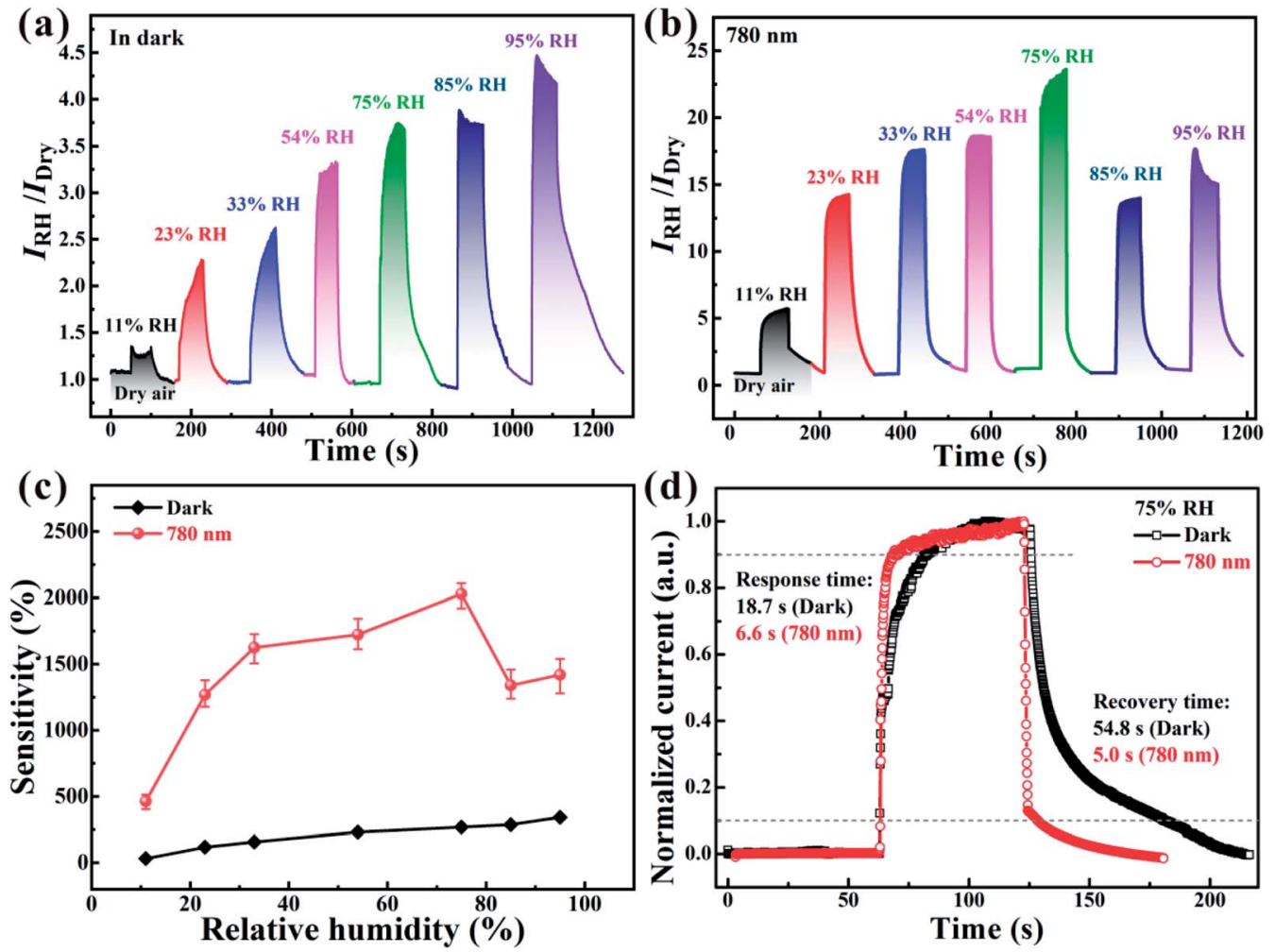

Fig. 6 The response properties of the PdSe $2 / S i N W A$ heterostructure to different $\mathrm{RH}$ values (a) in the dark and (b) under $780 \mathrm{~nm}$ illumination. (c) The dependence relationship between sensitivity and relative humidity in the dark and under $780 \mathrm{~nm}$ illumination. (d) The response and recovery time of the device to $75 \% \mathrm{RH}$ in the dark and under $780 \mathrm{~nm}$ illumination.

different RH values from $11 \%$ to $95 \%$ in the dark and under 780 $\mathrm{nm}$ illumination, respectively, at room temperature. It is observed that significant current response with good stability and repeatability is achieved at each of the $\mathrm{RH}$ values. The sensitivity $(S)$ of a humidity sensor can be defined by the following equation: ${ }^{60}$

$$
S=\frac{I_{\mathrm{RH}}-I_{\text {Dry }}}{I_{\text {Dry }}} \times 100 \%
$$

where $I_{\mathrm{RH}}$ and $I_{\text {Dry }}$ are the currents of the sensor in a humid atmosphere and under dry air conditions, respectively. Significantly, the $\mathrm{PdSe}_{2} / \mathrm{SiNWA}$ heterostructure shows greatly enhanced sensitivities under light illumination compared with the values in the dark (Fig. 6c). The statistical averages of sensitivities were calculated to be $462.7 \%, 1268.2 \%, 1625.1 \%$, $1722.8 \%, 2029.6 \%, 1339 \%$ and $1418.8 \%$ at $11 \%, 33 \%, 54 \%$, $75 \%, 85 \%$ and $95 \% \mathrm{RH}$ under light illumination, respectively, in contrast to the much smaller values of $32 \%, 118 \%, 157 \%, 231 \%$, $286 \%$ and $342 \%$ obtained correspondingly in the dark. The dependence relationship between the sensitivity and light intensity is plotted in Fig. S9. $\uparrow$ It can be clearly seen that the sensitivity of this humidity sensor is highly dependent on the incident light intensity, which becomes higher as the light intensity increases. In addition, the response speed also improved greatly under light illumination, as presented in Fig. $6 \mathrm{~d}$. The response and recovery times of $18.7 / 54.8 \mathrm{~s}$ in the dark at $75 \% \mathrm{RH}$ further improved to $6.6 / 5.0 \mathrm{~s}$ under light illumination, which are much faster than previously reported results. ${ }^{61-64}$ The long recovery time in the dark is believed to be related to the large surface-to-volume ratio of the 2D $\mathrm{PdSe}_{2} /$ SiNWA heterostructure, which will lead to the weak desorption of water vapour. ${ }^{65}$ It is expected that the response/recovery time could be further improved by the methods of increasing operating temperature and applying a large bias voltage to the heterojunction device. The enhanced performance of the $\mathrm{PdSe}_{2} /$ SiNWA heterostructure sensor can be attributed to the following reasons. In the dark, $\mathrm{H}_{2} \mathrm{O}$ will be adsorbed on the surface of the heterostructure in the form of active $\mathrm{OH}^{-}$groups and molecules, which will increase the conductivity of the device. ${ }^{66}$ Upon light illumination, the incident light will generate electron-hole pairs in the heterostructure device, and the holes will move to the device surface and oxidize the $\mathrm{OH}^{-}$groups on the surface. The remaining photo-generated electrons will contribute to the increased conductivity of the device at a relatively lower $\mathrm{RH}$ value. At a higher RH value, a monolayer of water will be formed at the surface of the heterostructure device. The photongenerated electrons and holes will capture the dissociated $\mathrm{H}^{+}$ and $\mathrm{OH}^{-}$ions from water vapor, leading to a lower photoconductance. ${ }^{67}$ The fast response process is due to the generation of electron-hole pairs under light illumination, which increases the carrier concentration in the heterostructure. And the fast recovery speeds could be attributed to the rapid recombination of holes and electrons after light illumination. ${ }^{68}$ Moreover, the device can retain its initial infrared response and 
humidity sensing properties with tiny degradation even after storage in air for 6 months without any protection (Fig.S10 $\dagger$ ), suggesting good air stability of the $\mathrm{PdSe}_{2} / \mathrm{SiNWA}_{\mathrm{N}}$ heterostructure device.

\section{Conclusions}

In summary, we have demonstrated a self-driven, broadband and polarization-sensitive photovoltaic detector made of the $\mathrm{PdSe}_{2} / \mathrm{SiNWA}$ mixed-dimensional vdW heterostructure. The device is highly sensitive to an ultra-broadband spectrum ranging from DUV to MIR (200 nm to $4.6 \mu \mathrm{m})$ with a high responsivity of $726 \mathrm{~mA} \mathrm{~W}^{-1}$, a large specific detectivity of $3.19 \times$ $10^{14}$ Jones, a fast response speed of $25.1 / 34 \mu \mathrm{s}$, and an ultrahigh polarization sensitivity of 75 . Based on the FDTD calculation, the remarkable device performance could be ascribed to the strong light confinement effect induced by Si nanostructures. Also, the as-assembled device can readily record simple images of "ZZU" and "MIR" produced under 980 and $4600 \mathrm{~nm}$ illumination, respectively, due to the excellent imaging capability. Moreover, this $\mathrm{PdSe}_{2} / \mathrm{SiNWA}$ heterostructure device showed light-enhanced humidity sensing properties with a high sensitivity and a fast response/recovery time. These remarkable results suggest that the $\mathrm{PdSe}_{2} / \mathrm{SiNWA}$ mixed-dimensional heterostructure device will have great potential application in highperformance polarization-sensitive broadband photodetection, infrared imaging and humidity sensing.

\section{Conflicts of interest}

There are no conflicts to declare.

\section{Acknowledgements}

This work was financially supported by the National Natural Science Foundation of China (Nos. 51821002, 91833303, 11974016 and 61605174), the Priority Academic Program Development of Jiangsu Higher Education Institutions (PAPD), the 111 Project, the Collaborative Innovation Center of Suzhou Nano Science and Technology (Nano-CIC), and the Natural Science Foundation of Anhui Province (808235830016).

\section{Notes and references}

1 A. K. Geim and K. S. Novoselov, Nat. Mater., 2007, 6, 183-191. 2 X. Wang, Z. Cheng, K. Xu, H. K. Tsang and J.-B. Xu, Nat. Photonics, 2013, 7, 888-891.

3 S. Du, W. Lu, A. Ali, P. Zhao, K. Shehzad, H. Guo, L. Ma, X. Liu, X. Pi, P. Wang, H. Fang, Z. Xu, C. Gao, Y. Dan, P. Tan, H. Wang, C. T. Lin, J. Yang, S. Dong, Z. Cheng, E. Li, W. Yin, J. Luo, B. Yu, T. Hasan, Y. Xu, W. Hu and X. Duan, Adv. Mater., 2017, 29, 1700463.

4 J. Zhu, D. Yang, Z. Yin, Q. Yan and H. Zhang, Small, 2014, 10, 3480-3498.

5 F. Koppens, T. Mueller, P. Avouris, A. Ferrari, M. Vitiello and M. Polini, Nat. Nanotechnol., 2014, 9, 780-793.
6 L.-H. Zeng, M.-Z. Wang, H. Hu, B. Nie, Y.-Q. Yu, C.-Y. Wu, L. Wang, J.-G. Hu, C. Xie, F.-X. Liang and L.-B. Luo, ACS Appl. Mater. Interfaces, 2013, 5, 9362-9366.

7 H. Li, Y. Li, A. Aljarb, Y. Shi and L. J. Li, Chem. Rev., 2018, 118, 6134-6150.

8 X. Zhang, H. Cheng and H. Zhang, Adv. Mater., 2017, 29, 1701704.

9 C. Kamal and M. Ezawa, Phys. Rev. B, 2015, 91, 085423.

10 Y. Yi, Z. Sun, J. Li, P. K. Chu and X. F. Yu, Small Methods, 2019, 3, 1900165.

11 J. Ji, X. Song, J. Liu, Z. Yan, C. Huo, S. Zhang, M. Su, L. Liao, W. Wang, Z. Ni, Y. Hao and H. Zeng, Nat. Commun., 2016, 7, 13352.

12 L. Tao, E. Cinquanta, D. Chiappe, C. Grazianetti, M. Fanciulli, M. Dubey, A. Molle and D. Akinwande, Nat. Nanotechnol., 2015, 10, 227.

13 P. Xiao, J. Mao, K. Ding, W. Luo, W. Hu, X. Zhang, X. Zhang and J. Jie, Adv. Mater., 2018, 30, 1801729.

14 J. Mao, Y. Yu, L. Wang, X. Zhang, Y. Wang, Z. Shao and J. Jie, Adv. Sci., 2016, 3, 1600018.

15 E. Wu, D. Wu, C. Jia, Y. Wang, H. Yuan, L. Zeng, T. Xu, Z. Shi, Y. Tian and X. Li, ACS Photonics, 2019, 6, 565-572.

16 R. Zhuo, Y. Wang, D. Wu, Z. Lou, Z. Shi, T. Xu, J. Xu, Y. Tian and X. Li, J. Mater. Chem. C, 2018, 6, 299-303.

17 D. J. Late, R. V. Kanawade, P. K. Kannan and C. S. Rout, Sens. Lett., 2016, 14, 1249-1254.

18 D. J. Late, T. Doneux and M. Bougouma, Appl. Phys. Lett., 2014, 105, 233103.

19 D. J. Late, Y.-K. Huang, B. Liu, J. Acharya, S. N. Shirodkar, J. Luo, A. Yan, D. Charles, U. V. Waghmare, V. P. Dravid and C. N. R. Rao, ACS Nano, 2013, 7, 4879-4891.

20 Y. Huang, E. Sutter, N. N. Shi, J. Zheng, T. Yang, D. Englund, H. J. Gao and P. Sutter, ACS Nano, 2015, 9, 10612-10620.

21 D. Parviz, F. Irin, S. A. Shah, S. Das, C. B. Sweeney and M. J. Green, Adv. Mater., 2016, 28, 8796-8818.

22 P. Ranjan, T. K. Sahu, R. Bhushan, S. S. Yamijala, D. J. Late, P. Kumar and A. Vinu, Adv. Mater., 2019, 31, e1900353.

23 Q. He, P. Li, Z. Wu, B. Yuan, Z. Luo, W. Yang, J. Liu, G. Cao, W. Zhang, Y. Shen, P. Zhang, S. Liu, G. Shao and Z. Yao, Adv. Mater., 2019, 31, e1901578.

24 P. Yang, X. Zou, Z. Zhang, M. Hong, J. Shi, S. Chen, J. Shu, L. Zhao, S. Jiang, X. Zhou, Y. Huan, C. Xie, P. Gao, Q. Chen, Q. Zhang, Z. Liu and Y. Zhang, Nat. Commun., 2018, 9, 979.

25 C. Tan, X. Cao, X. J. Wu, Q. He, J. Yang, X. Zhang, J. Chen, W. Zhao, S. Han, G. H. Nam, M. Sindoro and H. Zhang, Chem. Rev., 2017, 117, 6225-6331.

26 Y. Liu, N. O. Weiss, X. Duan, H.-C. Cheng, Y. Huang and X. Duan, Nat. Rev. Mater., 2016, 1, 16042.

27 D. Wu, Y. Wang, L. Zeng, C. Jia, E. Wu, T. Xu, Z. Shi, Y. Tian, X. Li and Y. H. Tsang, ACS Photonics, 2018, 5, 3820-3827.

28 L.-H. Zeng, D. Wu, S.-H. Lin, C. Xie, H.-Y. Yuan, W. Lu, S. P. Lau, Y. Chai, L.-B. Luo, Z.-J. Li and Y. H. Tsang, Adv. Funct. Mater., 2019, 29, 1806878.

29 L.-H. Zeng, Q.-M. Chen, Z.-X. Zhang, D. Wu, H. Yuan, Y.-Y. Li, W. Qarony, S. P. Lau, L.-B. Luo and Y. H. Tsang, Adv. Sci., 2019, 6, 1901134. 
30 M. Long, Y. Wang, P. Wang, X. Zhou, H. Xia, C. Luo, S. Huang, G. Zhang, H. Yan, Z. Fan, X. Wu, X. Chen, W. Lu and W. Hu, ACS Nano, 2019, 13, 2511-2519.

31 A. D. Oyedele, S. Yang, L. Liang, A. A. Puretzky, K. Wang, J. Zhang, P. Yu, P. R. Pudasaini, A. W. Ghosh, Z. Liu, C. M. Rouleau, B. G. Sumpter, M. F. Chisholm, W. Zhou, P. D. Rack, D. B. Geohegan and K. Xiao, J. Am. Chem. Soc., 2017, 139, 14090-14097.

32 E. Li, D. Wang, P. Fan, R. Zhang, Y.-Y. Zhang, G. Li, J. Mao, Y. Wang, X. Lin, S. Du and H.-J. Gao, Nano Res., 2018, 11, 5858-5865.

33 W. L. Chow, P. Yu, F. Liu, J. Hong, X. Wang, Q. Zeng, C. H. Hsu, C. Zhu, J. Zhou, X. Wang, J. Xia, J. Yan, Y. Chen, D. Wu, T. Yu, Z. Shen, H. Lin, C. Jin, B. K. Tay and Z. Liu, Adv. Mater., 2017, 29, 1602969.

34 Q. Liang, Q. Wang, Q. Zhang, J. Wei, S. X. Lim, R. Zhu, J. Hu, W. Wei, C. Lee, C. Sow, W. Zhang and A. T. S. Wee, Adv. Mater., 2019, 31, e1807609.

35 D. Jariwala, T. J. Marks and M. C. Hersam, Nat. Mater., 2017, 16, 170-181.

36 R. Zhuo, L. Zeng, H. Yuan, D. Wu, Y. Wang, Z. Shi, T. Xu, Y. Tian, X. Li and Y. H. Tsang, Nano Res., 2019, 12, 183-189. 37 D. Wu, J. Guo, J. Du, C. Xia, L. Zeng, Y. Tian, Z. Shi, Y. Tian, X. J. Li, Y. H. Tsang and J. Jie, ACS Nano, 2019, 13, 9907-9917. 38 Y. Wang, X. Huang, D. Wu, R. Zhuo, E. Wu, C. Jia, Z. Shi, T. Xu, Y. Tian and X. Li, J. Mater. Chem. C, 2018, 6, 48614865.

39 J. Wang, J. Han, X. Chen and X. Wang, InfoMat, 2019, 1, 3353.

40 H. Qiao, Z. Huang, X. Ren, S. Liu, Y. Zhang, X. Qi and H. Zhang, Adv. Opt. Mater., 2020, 8, 1900765.

41 R. A. Soref, Proc. IEEE, 1993, 81, 1687-1706.

42 Y. Cui, Z. H. Zhong, D. L. Wang, W. U. Wang and C. M. Lieber, Nano Lett., 2003, 3, 149-152.

43 M. H. R. Lankhorst, B. W. S. M. M. Ketelaars and R. A. M. Wolters, Nat. Mater., 2005, 4, 347-352.

44 D. Wu, Z. Lou, Y. Wang, Z. Yao, T. Xu, Z. Shi, J. Xu, Y. Tian, X. Li and Y. H. Tsang, Sol. Energy Mater. Sol. Cells, 2018, 182, 272-280.

45 L. Zeng, S. Lin, Z. Lou, H. Yuan, H. Long, Y. Li, W. Lu, S. P. Lau, D. Wu and Y. H. Tsang, NPG Asia Mater., 2018, 10, 352-362.

46 E. D. Palik, Handbook of Optical Constants of Solids, Academic Press, Orlando, 1985.

47 P. Wang, S. Liu, W. Luo, H. Fang, F. Gong, N. Guo, Z. G. Chen, J. Zou, Y. Huang, X. Zhou, J. Wang, X. Chen, W. Lu, F. Xiu and W. Hu, Adv. Mater., 2017, 29, 1604439.

48 L. Wang, J. Jie, Z. Shao, Q. Zhang, X. Zhang, Y. Wang, Z. Sun and S. T. Lee, Adv. Funct. Mater., 2015, 25, 2910-2919.
49 S.-C. Kung, W. E. van der Veer, F. Yang, K. C. Donavan and R. M. Penner, Nano Lett., 2010, 10, 1481-1485.

50 L. Dou, Y. M. Yang, J. You, Z. Hong, W. H. Chang, G. Li and Y. Yang, Nat. Commun., 2014, 5, 5404.

51 R. K. Chowdhury, R. Maiti, A. Ghorai, A. Midya and S. K. Ray, Nanoscale, 2016, 8, 13429-13436.

52 C. O. Kim, S. Kim, D. H. Shin, S. S. Kang, J. M. Kim, C. W. Jang, S. S. Joo, J. S. Lee, J. H. Kim, S. H. Choi and E. Hwang, Nat. Commun., 2014, 5, 3249.

53 L.-H. Zeng, S.-H. Lin, Z.-J. Li, Z.-X. Zhang, T.-F. Zhang, C. Xie, C.-H. Mak, Y. Chai, S. P. Lau, L.-B. Luo and Y. H. Tsang, Adv. Funct. Mater., 2018, 28, 1705970.

54 Y. Yang, S.-C. Liu, X. Wang, Z. Li, Y. Zhang, G. Zhang, D.-J. Xue and J.-S. Hu, Adv. Funct. Mater., 2019, 29, 1900411. 55 J. Bullock, M. Amani, J. Cho, Y.-Z. Chen, G. H. Ahn, V. Adinolfi, V. R. Shrestha, Y. Gao, K. B. Crozier, Y.-L. Chueh and A. Javey, Nat. Photonics, 2018, 12, 601-607. 56 L. Li, W. Han, L. Pi, P. Niu, J. Han, C. Wang, B. Su, H. Li, J. Xiong, Y. Bando and T. Zhai, InfoMat, 2019, 1, 54-73.

57 H. Yuan, X. Liu, F. Afshinmanesh, W. Li, G. Xu, J. Sun, B. Lian, A. G. Curto, G. Ye, Y. Hikita, Z. Shen, S. C. Zhang, X. Chen, M. Brongersma, H. Y. Hwang and Y. Cui, Nat. Nanotechnol., 2015, 10, 707-713.

58 W. Deng, X. Zhang, L. Huang, X. Xu, L. Wang, J. Wang, Q. Shang, S. T. Lee and J. Jie, Adv. Mater., 2016, 28, 22012208.

59 L. Li, Z. Lou and G. Shen, Adv. Funct. Mater., 2018, 28, 1705389.

60 A. S. Pawbake, R. G. Waykar, D. J. Late and S. R. Jadkar, ACS Appl. Mater. Interfaces, 2016, 8, 3359-3365.

61 Z. Lou, D. Wu, K. Bu, T. Xu, Z. Shi, J. Xu, Y. Tian and X. Li, J. Alloys Compd., 2017, 726, 632-637.

62 M. B. Erande, M. S. Pawar and D. J. Late, ACS Appl. Mater. Interfaces, 2016, 8, 11548-11556.

63 L. D. Bharatula, M. B. Erande, I. S. Mulla, C. S. Rout and D. J. Late, $R S C A d v ., 2016,6,105421-105427$.

64 A. S. Pawbake, S. R. Jadkar and D. J. Late, Mater. Res. Express, 2016, 3, 105038.

65 W. Li, E. Dai, G. Bai and J. Xu, Sens. Actuators, B, 2016, 237, 526-533.

66 Z. Chen and C. Lu, Sens. Lett., 2005, 3, 274-295.

67 Y. M. Juan, S. J. Chang, H. T. Hsueh, S. H. Wang, W. Y. Weng, T. C. Cheng and C. L. Wu, RSC Adv., 2015, 5, 84776-84781. 68 Y. Li, F. Della Valle, M. Simonnet, I. Yamada and J.-J. Delaunay, Appl. Phys. Lett., 2009, 94, 023110.

69 L. B. Luo, D. Wang, C. Xie, J. G. Hu, X. Y. Zhao and F. X. Liang, Adv. Funct. Mater., 2019, 29, 1900849. 